\title{
More options for climate scientists
}

\author{
The launch of Nature Climate Change provides a new outlet for climate researchers' work, while \\ Nature Geoscience and Nature will continue to publish climate studies.
}

In April 2011, a new journal will join the Nature pantheon. Nature Climate Change (http://www.nature.com/nclimate) will aim to publish papers on all aspects of climate change science, including the impacts of global warming on ecology, economy and policy. The launch will not affect the scope of Nature Geoscience; we will continue to provide a platform for research ranging from palaeoclimate and climate dynamics to carbon cycle research - or, in the language of the Intergovernmental Panel for Climate Change, all subject areas traditionally covered by Working Group I in The Physical Science Basis. Of course Nature, too, will continue unaffected, publishing on all natural science aspects of climate (and climate change) science.

Given the emphasis on climate impacts in Nature Climate Change, and its broad range of topics that fall outside the geosciences (for example, economics, sociology and psychology), we do not expect a large amount of overlap. However, Nature Climate Change will also cover climate change topics in the physical sciences that could just as well be published in Nature Geoscience or Nature. In these areas, Nature Climate Change will simply provide an additional publishing outlet.

In line with Nature Publishing Group's fundamental principles, the decision of where to submit a paper will lie entirely with the authors. A manuscript submitted to Nature Geoscience will not be transferred to Nature Climate Change (or vice versa) unless the authors explicitly request to make use of our transfer system (see http://go.nature. com/PY7jLh for details). If authors do decide to transfer their paper they will receive an independent editorial decision from the recipient journal, based on the merits of the paper and the editorial criteria of that journal.

When deciding where to submit their work, authors should consider which audience they would like to reach Nature Geoscience's readership of physical scientists that study solid Earth, planetary and climate sciences, or the equally broad anticipated audience of Nature Climate Change of policymakers and economists, as well as ecologists and climate researchers. We are confident that, in the long run, readers and authors will have little trouble navigating the new set of choices.

In the meantime, we would like to confirm to all potential authors - in the science of climate and climate change as much as in all the other fields of the Earth sciences - that we continue to welcome their most exciting work.

\section{The challenge of extremes}

\section{As the science of attributing climatic extremes to human actions matures, lawyers are working through the implications for their trade.}

Catastrophic floods not only destroy crops, houses and lives, as observed in recent months around the world. They also remind societies of their fundamental vulnerability to the forces of nature. Whether humans have in turn exacerbated the forces of nature by emitting greenhouse gases to the atmosphere has been an open question. Two new studies affirm. One reveals that human-induced emissions have contributed to the observed intensification of extreme rainfall events over parts of the Northern Hemisphere ${ }^{1}$. Another quantifies the impact of anthropogenic emissions on the risk of the floods ${ }^{2}$ experienced in the UK in autumn 2000.

A range of potentially damaging climatic extremes - storms, droughts, heatwaves and extreme precipitation - have been projected to become more frequent as global warming progresses. But the rarity of these extreme events makes it hard to detect trends in their frequency, determine causes, or quantify a potential contribution from anthropogenic greenhouse gas emissions (see News \& Views on page 142). This feat was achieved ${ }^{3}$ for the European heatwave in 2003, but not for relatively small-scale events, such as the bouts of extreme precipitation that lead to flooding. After a flood, however, it is much clearer who has been affected in monetary terms. Those people might be tempted to seek compensation.

A quantifiable change in flood risk that can be pinpointed to industrial greenhouse gas emissions could mean that they have a case. Climate change litigation - the idea that the people that lose property in a global-warming-related catastrophe could sue companies that emit greenhouse gases ${ }^{4}-$ depends on scientists' ability to prove a causal link between individual natural disasters and a slowly changing climate. Such attribution is possible only in a probabilistic sense. For example, it is very likely that the flood risk was raised by more than 20\% in England and Wales in 2000 because of human-made greenhouse gas emissions ${ }^{2}$.

But a risk increase by as little as $20 \%$, at a $90 \%$ level of probability, may not be deemed sufficient in a courtroom to claim compensation. And it is not entirely clear yet how the probabilistic nature of the argument would work in legal frameworks that were originally built around proof of causation. Nor is it obvious how the blame could be distributed between various emitters of greenhouse gases. That said, it seems that the science is far enough advanced for the legal profession to become interested.

When eight US states and New York City filed a lawsuit in 2004 against five US power companies for contributing to global warming, the complaint was initially dismissed. However, the case has been reopened on appeal, and is awaiting a decision from the Supreme Court at present. If the complaint is successful, emitters will consider trading or simply reducing carbon dioxide emissions more seriously. The law may yet come to the aid of climate stabilization.

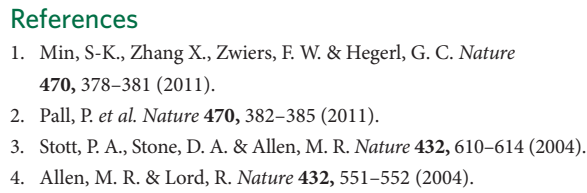

Published online: 20 February 2011 